\title{
Relationship between Reading Anxiety, Reading Strategies and Language Competence of Rural ESL Secondary Learners
}

\author{
Sharon Litad Petrus, Parilah Md Shah \\ University Kebangsaan Malaysia, Bangi, Malaysia \\ Email: sharez_lee@yahoo.com,drparila@gmail.com
}

How to cite this paper: Petrus, S. L., \& Shah, P. M. (2020). Relationship between Reading Anxiety, Reading Strategies and Language Competence of Rural ESL Secondary Learners. Creative Education, 11, 126-142.

https://doi.org/10.4236/ce.2020.112010

Received: January 22, 2020

Accepted: February 18, 2020

Published: February 21, 2020

Copyright $\odot 2020$ by author(s) and Scientific Research Publishing Inc. This work is licensed under the Creative Commons Attribution International License (CC BY 4.0).

http://creativecommons.org/licenses/by/4.0/

(c) (i) Open Access

\begin{abstract}
Learning English as a second language (ESL) for rural secondary learners is challenging, especially related to reading skills. This challenge causes anxiety to arise among rural ESL secondary learners while reading English related reading materials, which indirectly affects their language competence. The problem is overcome as learners seek to utilise suitable strategies as they read any English reading materials. The anxiety that rural ESL secondary learners faced in their reading of English material affects their language competence which is reflected in their English paper grades and strategies employed while reading contributes to a better result which reflects their language competence. This paper discusses a survey that explores the relationship between reading anxiety, strategies and language competence among $n=139$ Form 4 secondary rural ESL learners. Two instruments, namely, EFL Reading Anxiety Instrument (EFLRAI) and the Survey of Reading Strategies (SORS), were employed to measure their anxiety level and reading strategies respectively. Rural ESL learners' language competence is based on their first examination of English grade. The result shows that there is a weak negative correlation between reading anxiety language competence and a weak positive correlation between reading strategies and language competence. This study implies that rural ESL learners experience medium level of reading anxiety when reading English materials and the use of strategies correlates positively with language competence. Although reading anxiety is not strongly experienced by rural ESL learners, yet, employing suitable reading strategies enhances learners' language competence.
\end{abstract}

\section{Keywords}

Reading Anxiety, Reading Strategies, Language Competence 


\section{Introduction}

In Malaysia, ESL learners sit for a public examination known as Sijil Pelajaran Malaysia (SPM) at the end of their secondary school years in form five. The exam for English subject consists of two papers Paper 1 (Directed Writing and Continuous Writing) and Paper 2 (questions on understanding vocabulary, grammar, information transfer, reading comprehension, summary, poem and novel). The percentage of Paper 2 is $70 \%$. Hence, the learners must read and understand the messages in different contexts provided. Therefore, a learner should have a strong reading skill to be able to process the vocabulary, phrases and sentences read because the content delivers different messages. In addition, it is to enable them to understand the cultural context that is read in the paper. Having strong reading skills enables learners to have reduced reading anxiety.

However, when sitting for an examination, learners engage in texts that are unfamiliar to them containing unfamiliar words and unfamiliar cultural context. Sometimes, they recognise the words read yet unable to decode their meaning. Thus reading anxiety sets in among ESL learners especially among rural ESL learners as they are unsuccessful in digesting the text. Reading in another language either foreign language or second language is found to be an arduous activity and anxiety provoking (Song, 2018). When reading becomes provoking for the reader, reading strategies should be employed as learners become engaged better with the text read (Nordin, Rashid, Zubir, \& Sadjirin, 2013). Reading activity is enhanced when suitable reading strategies are employed when ELS learners are able to interpret and decode, interact with the text, and it involves active, cognitive and thinking processes (Qanwal \& Karim, 2014). When a learner fails to interact with the text read, it triggers anxiety and the need for them to engage with suitable reading strategies is important to overcome it to do better in their English exam which reflects their language competence.

Reading is a challenging activity as it is a complex process, problem-solving and situationally bounded (Schoenbach, Greenleaf, Cziko, \& Hurwitz, 1990). When one does not adopt reading habits into their lifestyle, one's vocabulary bank becomes limited. Learners who are not an avid reader will find reading English printed text challenging and face difficulty in understanding it. Furthermore, reading requires readers to make sense of what they see as it entails learners to communicate with the lettering words they read. When a language is a tool used for communication and the message is its main focus, it becomes a tool to understand the message in the materials that learners read and a method to acquire a language in a receptive way (Acevedo \& Forero, 2016; Ngabut, 2015). According to Ellis (2006), it is believed that when a learner reads a reading comprehension in a new language, it is their previous knowledge that would influence their understanding and interpretation of it (Karimi et al., 2019). Hence, the importance of reading is fundamental.

Researches on various aspects pertaining to the learning of the second language have been actively carried out and one aspect of concern is related to the 
affective filter factor; anxiety (Deb, 2018). Horwitz, Horwitz, and Cope (1986) described anxiety as "a feeling of tension, apprehension, nervousness, and worry which is associated with an arousal of the autonomic nervous system" known to be subjective and this affective factor is vital in the second language learning (Deb, 2018). With relation to reading skills in the learning of English as a second language (ESL), the affective filter is prevalent as ESL learners encounter reading anxiety that triggers this autonomic nervous system as they read English related materials. This is crucial for learners in rural area as they need to counter this predicament to lower and ease their anxiety.

For this research, the samples of the studies are from the rural area of Baram district which is situated to the north of Sarawak. A large population of a diverse community lives in this district. School children in Baram district attend residential schools away from their parents as their longhouses are far from where the schools are. Those who are staying within the proximity of the schools attend it from their home on a daily basis. The English language is taught in a formal setting. Outside school hours, rural ESL learners do not have the environment to practice the English language. With limited opportunity to practice the language and their attitude towards reading English materials lead to emotional distress that creates anxiety whenever they read English materials. Hence, appropriate strategies should be employed to garner better language competence.

In order to explore reading anxiety among rural ESL learners in Baram district, Sarawak, a survey instrument is utilized in getting their response. It is designed by Zoghi (2012) in response to the shortcomings of the Foreign Language Reading Anxiety Survey (FLRAS) developed by Saito et al. (1999) and it reveals a multidimensional of English as a Foreign Language (EFL) reading anxiety which is applicable to ESL reading anxiety (Zoghi \& Alivandivafa, 2014). The instrument consists of factors leading to reading anxiety and possesses psychometric properties of the English as a Foreign Language Reading Anxiety Inventory (EFLRAI). This instrument is adapted to be used in this research.

In addition, a specific tool designed by Mokhtari and Sheorey (2002), known as Survey of Reading Strategies (SORS) is adapted to investigate learners' reading strategies employed. The effort of understanding the process of pre, while and post-reading is crucial for ESL learners to benefit from the English materials read. ESL learners may use these strategies listed in the instrument to assist them in reading English texts as meaning is being constructed and information is gained from the text they interact with when reading at a fast rate (Chen \& Chen, 2015).

In this research, rural ESL learners' language competence is measured by using their first semester English paper grade in Form 4. Language competence is believed to be a broad term for which it includes "linguistic or grammatical competence, discourse competence, sociolinguistic or socio-cultural competence" as it refers to textual competence (Manitoba Curriculum Framework of Outcomes, 2007: p. 19). It is further defined to a person's ability to interpret and 
produce meaningful meaning to texts they read and relate it to proper situations that they are used to as they deal with the knowledge of the language.

In Malaysia, the focus of reading anxiety research was done mostly at the tertiary level, for example, research done by Rajab et al. (2012), Zarei (2014), and Im (2015). However, the need to understand reading anxiety among the secondary school level, particularly in other regions is crucial. This is the gap that needs to be explored, especially among rural ESL learners, because they contribute to the country's average grade performance $(G P N K)$ for English subject. Hence, investigating if reading anxiety is a factor that affects language competence is pivotal.

In light of language usage on a daily basis, rural ESL learners use their mother tongue and Bahasa Malaysia. For rural folks in Malaysia, the usage of the English language becomes other languages, although, in the Malaysian context, the English language is as a second language. This is due to the fact that the English language is only acquired in school as another subject to be learned. This is supported by Shah et al. (2016) stated that children in the rural area only speak Bahasa Malaysia and English when they enter school since Bahasa Malaysia is the medium of instruction in schools throughout Malaysia. When in school, they learn the English language through all four skills, speaking, listening, reading and writing. Krashen (2004) personally believes that the learning of second language can be acquired through reading as exposing learners to comprehensible input that are above their proficiency enable learners to acquire the language successfully (Pascual, 2019).

Reading anxiety, reading strategies and language competence are three variables that contribute to the learning of English as a second language, examining the correlation among all these variables are crucial in understanding rural ESL learners experience at acquiring the language through reading. The objectives of this research are, therefore 1) to examine the level of rural ESL learners' reading anxiety 2) to investigate the correlation between reading anxiety and language competence of rural ESL learners and 3) to explore the correlation between reading strategies and language competence of rural ESL learners. This research attempts to answer three research questions. They are; a) What is the level of reading anxiety among rural ESL secondary learners? b) Is there a correlation between reading anxiety and language competence of rural ESL learners? c) Is there a correlation between reading strategies and language competence of rural ESL learners? There are two null hypotheses (Ho1) that is to be answered (i) There is no significant correlation that exists between reading anxiety and language competence of rural ESL learners (ii) There is no significant correlation between reading strategies and language competence of rural ESL learners.

This paper will further discuss studies related methodology applied, report on the data analysed and discussion on the findings. It also states the implication and suggestions. 


\section{Literature Review}

In the matter of acquiring a second language, there are elements that exist which hamper the process. One element is reading anxiety which is related to affective filter. As reading anxiety is one element that distorts the acquiring of the second language, it is important to explore its extension on a different sample in other regions and how reading strategies function at overcoming it. However, studies regarding reading anxiety among secondary school ESL learners are limited and there is a need to add to the literature.

Researches pertaining to second language learning have been carried out for many decades to understand learners' learning experience in the area of speaking, writing, listening and reading skills in relation to affective contributors which are self-efficacy, anxiety, and motivation (Deb, 2018). As anxiety is linked to speaking skills, recent research has found that ESL learners face anxiety related to reading, leading to poor reading performance and contributing contrast result to speaking (Song, 2018). The anxiety contributor with relation to reading skill has drawn researchers' attention to unravel the effect of reading anxiety on EFL learners (Sari \& Sumatra, 2017; Aisyah, 2017; Muhlis, 2017; Zarei \& Ghoushchi, 2018) and also on ESL learners (Kiya, 2015; Kilinc \& Yenen, 2015; Mei \& Michelle, 2014).

In order to ease this anxiety, Krashen (1981) suggested that learners should have a medium for anxiety-free environment that help ease their anxiety (Karbalaei, 2015). Reading strategies can be a medium that eases learners reading anxiety because when the learners are familiar with and employ suitable reading strategies, they will be able to answer questions related to reading comprehension with ease.

In one research done by Sari \& Sumatra (2017) among 103 EFL teachers learners in Palembang, it is reported that there was no significant relationship between reading anxiety and reading strategies. With regard to reading anxiety alone, a junior high school in Bandung investigated by Aisyah (2017), they were found to have a medium level. It revealed that the cause of their reading anxiety was due to unknown vocabulary, unfamiliar topic and unfamiliar culture. In addition, they were also found to fear of making errors. In another research done among senior high school learners in Palembang by Muhlis (2017) it was found to report similar results with Aisyah (2017) for source of reading anxiety. It can be summarized that they report the same result as both samples are from the same county, Indonesia and English is learned as a foreign language in secondary schools. Zarei and Ghoushchi (2018) who did research on Iranian EFL learners related to corrective feedback types, which are self-feedback, teacher feedback, and peer feedback. The result shows that reading anxiety is most prevalent when learners get feedback from teachers, followed by peer feedback and lastly self-feedback.

The effect of reading anxiety on ESL learners brought about different results compared to EFL learners as other aspects of variables are being explored. In 
another research done by Kiya (2015) on Iranian University students reflected a positive relationship between EFL classroom and reading anxiety. Kilinc and Yenen (2015) investigated the level of reading anxiety based on Melanlioglu's (2014) 5 Likert reading anxiety scale consist of four sub-dimensions which are planning of reading process, factors supporting reading, reading comprehension and analysis found that the respondents "sometimes" face anxiety in reading comprehension and analysis and found to "rarely" have any anxiety in the area of planning of reading and factors supporting reading. However, research was done by Mei and Michelle (2014) exploring the relationship between reading anxiety and reading performance among Chinese learners learning English as a second language, it was found that there is a negative relation between L1 and L2 reading performance and reading anxiety.

In Malaysia, Rajab et al. (2012) conducted a study on reading anxiety levels faced by 91 final year Science and Non-Science undergraduates in Universiti Teknologi Malaysia with relation to their reading performance. It was found that there is a difference in the level of L2 reading anxiety between science and non-science group in UTM. With regard to determining the relationship between reading anxiety and course grades, it resulted in a negative correlation and it is very low.

As reading anxiety affects ESL learners reading performance and causes personal phobia as they read, some may experience anxiety at a minimum level when others at an intense level (Kilinc \& Yenen, 2015). Researches on reading strategies have been carried out in the light of this issue. Qanwal and Karim (2014) research was to identify the correlation between reading strategies and reading comprehension among higher level L2 learners of English in Pakistan shows a positive correlation between reading strategies instruction and learners' proficiency. In an action research design, applying the Stringer's Action Research Model and using the Bloom's taxonomy as a reference tool to investigate the critical reading strategies employed by Iranian EFL learners found that successful readers know when and how to deliberately apply suitable strategies to restore their own comprehension (Nasrollahi, Krishnasamy, \& Noor, 2015).

In another research done by Sultana (2016) among Bangladeshi learners, it is found that they employ scanning, rereading, summarizing, using prior knowledge and discuss with other people when reading because learning English other than the language they use on a daily basis may be challenging for the students. In addition, learners are often found to reflect on their reading strategies which are crucial to understanding their own reading process for which McGrath et al. (2016) believe that this process enables them to continuously find better reading strategies that would help them to retain the knowledge.

Another research done locally in Malaysia by Semtin and Maniam (2015) investigated reading strategies that employed cognitive and metacognitive strategies among 90 Malaysian secondary school students in Kapit division. It reported that the learners frequently use the translation strategy which is cognitive 
strategies. Metacognitive strategies show that the learners frequently employ selective attention requiring learners to pay attention to the text and memorise them prior to reading the text (Semtin \& Maniam, 2015). Translation method and employing selective attention when reading is crucially used by these learners as a suburban school does not have the environment that would motivate the learners to practice the English language.

When ESL learners are taught English language, it has to be taught based on learning principles and the instilling of language competence in the learners' themselves is the catalyst and foundation of the learning process (Liu, 2019). Defining language competence has become more comprehensive and scientific (pg. 119). According to Cheng and Zhao (2016), language competence is described as the learners' ability to successfully acquire basic language skills, learning capacities, thinking strategies and cultural competencies related to the English language. Moreover, language competence, as reflected in the teaching content, is more towards exam-oriented, focuses on learners' reading and writing skills to prepare them for examinations disregarding learners' speaking and listening skills which are crucial for real-life situations (Liu, 2019).

In Malaysian context, English language competence has already been instilled among the learners since primary school with the introduction of New Primary Schools Curriculum or Kurikulum Baru Sekolah Rendah (KBSR) implemented in 1983. It consists of the four skills; listening, speaking, reading and writing and it continued to be integrated in the secondary school curriculum through the Integrated Secondary Schools Curriculum or Kurikulum Bersepadu Sekolah Menengah (KBSM) for which learners have the opportunities to "engage in wider reading for enjoyment and self-development, as well as to develop an understanding of other societies, cultures, values and traditions" (Darmi \& Albion, 2013: p. 4). However, the low unemployment rate among Malaysian is linked to poor command in the English language, and poor communication skills among fresh graduates are worrisome to the education ministry (Hossain et al., 2018). To address this issue, the English curriculum has been revamped and transformed as part of Malaysia Education Blueprint 2013-2025 planning. Common European Framework Reference (CEFR) was implemented since 2017, beginning with form one and form four English learners. They are expected to undergo it in the year 2020 .

\section{Methodology}

\subsection{Survey Design and Instruments}

This research is a survey design and data is collected through questionnaire, where respondents answered according to their experience. The survey design used in collecting the data is a cross-sectional survey design for which it is able to measure and examine respondents' current attitudes, beliefs, opinions or practices on certain subject. For this research it is pertaining to respondents' reading anxiety and reading strategies. 
Questionnaire was employed in getting information from respondents. There are several principles to the use of questionnaire for this research. Firstly, it enables researcher to explore the emotional responses of the respondents' experiences and thoughts with relation to reading English which ignites reading anxiety. Secondly, it is to discover the reading strategies that respondents employ when reading English materials. In addition, the use of questionnaire is easy to administer as it is designed with closed-ended questions consisted of a standard set of questions. Researcher is able to quantify and analyse the answers from the respondents as Likert-scale is used to determine their response. Thus, the finding from this survey hopes to add to the pool of literature on the subject.

The instrument used for this survey consists of four sections: 1) 10 items of reading comprehension, 2) personal details which require the learners to answer some demographic pertaining to their gender, age, English grade and their ethnic group. 3) Part one in the questionnaire is on reading anxiety and 4) part two investigates their reading strategies.

The researcher adapted 27 construct items from English as a Foreign Language Reading Anxiety Inventory (EFLRAI) designed by Zoghi (2012). It was categorized into four degrees of Likert scale from Level 1: totally disagree to Level 4: totally agree. It has an internal consistency of Cronbach's alpha $(\alpha=0.89)$ and an acceptable correlation coefficient $(r=0.97)$.

The reading strategies adapted 30 construct items from Mokhtari and Sheorey (2002), which is known as a Survey of Reading Strategies (SORS). The item statements were categorized into five degrees of Likert scale from Level 1: I never or almost never do this to Level 5: I always or almost always do this. It has an internal consistency of Cronbach's alpha of $(\alpha=0.93)$. The learners were to answer according to their personal experience when reading English materials.

\subsection{Samples}

The sample is a group of $139(n=139)$ rural ESL learners from one of the schools in Baram district, Sarawak. They are form four secondary school learners aged 16 years old. The form four populations in that school are 213 learners and they are from different ethnicity.

Prior to determining the samples, the school was randomly selected from among the other schools in the Baram district. However, the samples who are the respondents are selected through convenient sampling and that generalizability is limited to learners that have similar characteristics as the learners in this school. In order to determine the sample size, although all the 213 form four learners were asked to answer the questionnaire, yet, only 139 learners $(n=139)$ was randomly selected for the data analysis. This is determined based on Krejcie and Morgan (1970) sample size table. The process of selecting the respondents based on the sample size was done using the SPSS 20.

The sample comprised of 62 male (44.6\%) and 77 (55.4\%) female from different ethnicity. The largest community of samples collected is from the Iban eth- 
nic with a total number of $51(36.7 \%)$ respondents. There were $13(9.4 \%)$ Chinese respondents, 15 (10.8\%) Penan respondents, 11 (7.9\%) Kelabit respondents, and $15(10.8 \%)$ Kenyah respondents. There were 9 (6.5\%) Malay, 7 (5.0\%) Kayan, 6 (4.3\%) Berawan, 3 Bidayuh (2.2\%), 2 (1.4\%) Murut, 2 (1.4\%) Kiput, and $2(1.4 \%)$ Bisaya respondents. Melanau, Lun Bawang and Kadazan each represented with 1 respondents make up to $2.1 \%$ of the samples.

In terms of language competence which was based on their first semester English grades, it reported that $35(25.2 \%)$ were poor learners which reflected with grade "G", 72 (51.8\%) got fair result which represented grade "E and D", 28 (20.1\%) obtained good result which was reflected with grade "C and B" and only $4(2.9 \%)$ got excellent result which is reflected with grade " $\mathrm{A}$ ".

\subsection{Data Collection Procedure}

Prior to collecting the data, the researcher had to acquire permission from the research department of Malaysia, the state education ministry, district education department as well as the school administrator.

In addition, the researcher had to also observe several ethical factors preceding the research. For example, researcher had to decide on the best design to use, identify the research questions and hypothesis for the research, identify the samples, determining the survey design and adhere to data collection procedures. Researcher also had to select suitable instruments to be used to obtain information needed, administer the instrument, analyse the data based on research question and hypotheses using suitable programme and lastly report the findings. These are the general process of research (Cresswell, 2012).

Prior to answering the actual questionnaire, the participants were to respond to one reading comprehension text, which was divided into three parts; personal details, reading anxiety and reading strategies. These elements are sufficient to elicit enough data to form concrete shreds of evidence to explore the correlation between the rural ESL learner's reading anxiety and strategies with their language competence pertaining to the English language. In addition, form 4 learners were chosen as respondents. This batch of form 4 happens to be the last batch undergoing the former Sijil Pelajaran Malaysia (SPM) English format based on the Kurikulum Bersepadu Sekolah Menengah (KBSM) in the year 2020. In the year 2022, Malaysian SPM Candidates will sit for SPM English paper based on the Common European Framework of Reference (CEFR), a tool to measure learners' language proficiency. Participants were able to answer the questionnaire without having the researcher or teacher assisting in translating words to Bahasa Malaysia because the questionnaires came with a translated version (Bahasa Malaysia) for each construct items. Samples were given $45 \mathrm{mi}$ nutes to answer the reading comprehension and the questionnaires.

\subsection{Data Analysis}

The data analysis was tabulated once the researcher collected the questionnaires. 
The data were analysed using the SPSS version 20. Data was tabulated according to the research questions. First, the descriptive statistics; frequency and percentage was used to gauge rural ESL secondary learners' level of reading anxiety. Then, inferential statistic: a simple Pearson product-moment correlation coefficient was performed to explore the correlations between variables; reading anxiety with language competence, reading strategies and language competence. It was also to measure the strength between the variables.

\section{Findings and Discussions}

\subsection{Findings}

Prior to investigating the correlation between reading anxiety and language competence, the level of reading anxiety among these rural ESL Secondary learners were tabulated from their mean score to find out their level of reading anxiety. The result is featured in Table 1.

The result in Table 1 portrayed that the rural ESL secondary learners have a medium level of reading anxiety, of which it is represented by 89 learners (64\%). There are 4 (2.9\%) learners with a low level of reading anxiety and $46(33.1 \%)$ learners with a high level of reading anxiety.

The result that answers the research question "Is there a correlation between reading anxiety and language competence of rural ESL learners?" is shown in Table 2. This research question is to investigate the relationship between rural ESL learners' reading anxiety and language competence. In order to solve this, a correlation procedure was used for this purpose.

From Table 2, the Pearson product-moment correlation was run to determine the relationship between reading anxiety and language competence. There was a weak, negative correlation between reading anxiety and language competence which was statistically not significant, $r=-0.041, \mathrm{n}=139, p=0.632(p>0.05)$. This indicates that the null hypothesis (Hol) is rejected.

Similar correlation procedure was done to answer the second research question

Table 1. Rural ESL secondary learners' level of reading anxiety.

\begin{tabular}{ccc}
\hline Level of reading anxiety & Frequency & Percentage (\%) \\
\hline Low & 4 & 2.9 \\
Medium & 89 & 64.0 \\
High & 46 & 33.1 \\
\hline
\end{tabular}

Table 2. Correlation between reading anxiety and language competence.

\begin{tabular}{cccc}
\hline & & Language Competence & Comment \\
\hline Reading Anxiety & Pearson Correlation & -0.041 & \\
Sig. (2-Tailed) & 0.632 & Not Significant \\
$\mathrm{N}$ & 139 & \\
\hline
\end{tabular}


Table 3. Correlation between reading strategies and language competence.

\begin{tabular}{cccc}
\hline & & Language Competence & Comment \\
\hline Reading Strategies & Pearson Correlation & $0.318^{* *}$ & \\
Sig. (2-Tailed) & 0.000 & $\begin{array}{c}\text { Significant at least at } \\
\text { the } 0.01 \text { level }\end{array}$ \\
$\mathrm{N}$ & 139 & \\
\hline
\end{tabular}

which is "Is there a correlation between reading strategies and language competence of rural ESL learners?". This research question is to investigate the relationship between rural ESL learners' use of reading strategies and language competence. Table 3 shows the results of the correlation between the two variables.

From Table 3, the Pearson product-moment correlation was computed to determine the relationship between reading strategies and language competence. The result shows a weak positive correlation between reading strategies and language competence which is statistically significant, $r=0.318, \mathrm{n}=139, p<$ 0.05 . This indicates that the null hypothesis (Hol) is accepted.

\subsection{Discussions}

The result in Table 1, which portrayed rural ESL secondary learners have a medium level of reading anxiety, is similar to the finding that was obtained by Aisyah (2017) and Muhlis (2017). Learners have a medium level of reading anxiety as English is a second language in Malaysia. Although English is a third language or known as other languages for rural folks, yet in schools, they learn the same syllabus and are using the same English textbooks as those learners in the urban and suburban learners.

The result in Table 2, featured a very low correlation, meant to show that the level of reading anxiety does not have a big impact and it does not influence rural ESL learners' increase or decrease grade in their language competence. This result is similar to the research done by Rajab et al. (2012) where reading anxiety of tertiary learners was also negatively correlated with their course grade. Although the two findings are comparatively done at different levels, yet it leads to a negative correlation between the two variables. This is the case for Malaysian rural ESL secondary learners because they have been exposed to the English language through formal education since the age of seven years old or even earlier. In addition, rural ESL secondary learners do not think reading in English triggers reading anxiety as Table 1 reports that they have medium level of reading anxiety. It can also be suggested that they are not worried even when they come across vocabulary that they do not understand.

In addition, the existence of a weak correlation between reading anxiety and language competence among rural ESL learners is that rural ESL learners in the interior of Baram district in Sarawak region have access to the internet via mo- 
bile phones, which enable them to have access to various English related materials online. Thus, their performance in language competence is poor as they do not apply the right strategies when reading. Applying the correct strategies when learning and reading another language is crucial as this enables learners to cope with the complex process of learning and at the same time, when often applied, it regulates the learning of second language (Martinez, 1996).

Although rural ESL learners are not exposed to the actual culture of the Native English speakers, yet, they do not feel anxious about reading in English materials although they have poor language competence themselves. It is due to the fact that they have been reading a second language (L2) that is in English since they have learned English over the 11 years of formal education. This is as explained by Rajab et al. (2012) as the respondents do not feel anxious about reading English materials as compared to other languages.

Moreover, these rural ESL learners do not have high reading anxiety and are only reported to be at medium level because they are found to be familiar with the English words found in the reading comprehension texts in the examination. Generally, the Malaysian English curriculum specifications provide teachers with lists of words for which learners are to learn and to be familiar with them. For form four ESL learners, teachers are provided with certain number of words in the curriculum specifications. These words are common words and known as high-frequency words. However, although teachers are encouraged to expose learners to the suggested words provided in the specifications, yet some ESL learners may find it difficult to remember these words when it is not used in their daily conversation or in their writing.

Since rural ESL learners perceive English as other languages rather than a second language, the possibility of them using the English language outside of classroom and school is slim to not at all, yet it does not lead to reading anxiety. In addition, rural schoolchildren only learn English during their English lessons in school (Che Musa et al., 2012). This is in contrast to the findings done by Aisyah (2017) as the source of anxiety for her participants was due to unknown vocabulary. However, this is not the case for these rural ESL learners because English teachers provide English reading comprehension materials to the learners in preparation for SPM 1119 English paper. This explains the weak correlation between reading anxiety and language competence.

With relation to reading strategies, it is found that the relationship between rural ESL learners' use of reading strategies and language competence led to a weak positive correlation. As the p-value is at $0.000(p<0.05)$ level of significance, it means that reading strategies do give an impact to the grade of students' language competence.

This is similar to the result obtained by Qanwal and Karim (2014), who found that there is a positive correlation with reading strategies used and language proficiency among higher level L2 Pakistan ESL learners. When a rural ESL learner employs reading strategies to assist them as they read English materials, these 
strategies become a supplement for them to comprehend the input that they read. Reading strategies acts as a medium in reducing reading anxiety enabling rural ESL learners to absorb more comprehensible input as they read. In addition, the use of reading strategies benefits learners as it brings positive impact in terms of achievement (Maishara, Md. Rashid, Syed Zubir, \& Sadjirin, 2013).

Since the relationship between the two variables is a weak correlation, it gives a connotation that the relationship between the two is present. Although the impact of one variable on the other is significant, yet there are other factors that would contribute to a stronger correlation that affect learners' language competence. Other factors that would contribute to it might be learners' motivation, attitude, time spend reading English materials and time spend doing English comprehension during English lessons in the classroom. These other factors affect one's language competence.

English teachers play an important role in introducing learning strategies to learners. One learning strategies that may be beneficial is to introduce suitable reading strategies to aid learners in their reading of English materials. This is extremely helpful for rural ESL learners. When teachers introduce suitable reading strategies to learners, learners' reading will be less hampered and it enhances their progress in reading. As Krashen (1981) stated that a learner's reading anxiety should be reduced in order to be free from anxiety to function to the maximum (Karbalaei, 2015).

When learners are unable to cognitively process what they read without employing any suitable strategies while reading, this leads to reading anxiety as rural ESL learners are unable to process the words, phrases and sentences they read as they struggle to make sense of what they read. Teachers are responsible for modeling various language learning strategies, especially reading strategies to school children. For rural ESL learners, their only source of being exposed to the English language and knowing the strategies to learn English is from their English teachers besides electronic medium and materials. This is supported by $\mathrm{Yu}$ nus and Mat (2014), as cited in Mookiah and Yunus (2016), stating that rural primary pupils in the Malaysian context should be made aware of the strategies in different writing tasks and teachers are to teach the pupils these as to develop an independent learner. When concern about primary school pupils is made aware, secondary school learners should also be concern about strategies that would assist them in their reading. This is especially crucial for rural ESL learners.

\section{Conclusion}

Exploring and investigating the subject of reading anxiety may be on the rise. It is indeed a significant subject to be studied to better understand the problems that contribute to the low language proficiency among Malaysians especially among rural ESL secondary learners which is reflected in their English grade which determines their level of language competence. Although the findings reported that rural ESL learners are found to have medium level of reading anxiety 
and that reading anxiety does not influence learners' language competence, it had ruled out the fact that learners' English examination grade is influenced by worries and anxiety they faced while reading.

There are several significances that this research brings about. First, as rural ESL learners are found to have a medium level of reading anxiety and reflect a low correlation to language competence, so rural ESL secondary learners should engage more in reading English related materials to be able to improve their language competence. This is because they hardly find English language difficult to be understood.

Secondly, this study is significant to educators because it enlightens them to the fact that rural ESL secondary learners have medium level of reading anxiety. This enables them to cease thinking that English language is difficult for rural ESL secondary learners because learners who have medium level of reading anxiety can be improved to having low reading anxiety when English teachers expose them to more and a variety of English related reading materials. This will also increase learners' vocabulary bank and they will be able to improve in their language competence.

In addition, rural ESL secondary learners should explore the usage of various reading strategies that would help enhance their learning through reading. Since reading strategies showed a positive low correlation with language competence, it is wise to apply suitable reading strategies when reading English materials which enhance their potential of getting better English grade that reflects their language competence. Moreover, English language teachers should model the use of reading strategies to their students, especially helping those in the rural area as reading is one skill of how ESL learners acquire the language. Teachers ought to incorporate 21st-century learning activities to assist ESL learners in mastering their language competence. Reading activity should be emphasized in the classroom as reading is when learners learn correct sentence structure besides learning new vocabulary and get themselves familiar with new words.

There are a few implications to this study. Since this paper discusses the relationship between reading anxiety, reading strategies and language competence was researched based on a convenient sampling, the result may only be generalized to learners with similar characteristics. In addition, the number of samples was also limited which contributed to the result of the findings. However, in order for the findings to be applicable among larger population of rural ESL learners, an increase to the sampling size as well as stratified sampling should be employed. In addition, to enhance better understanding on why rural ESL secondary learners have medium level of reading anxiety, qualitative research through interviews and observations may be carried out to gain insights from both learners and teachers.

In addition, suggestion to further investigate the types of reading strategies modeled by teachers should be carried out and finding how it correlates with learner's language competence would be helpful as a teacher's technique in ap- 
proaching a problem through a devised solution is worth to explore. In addition, explore time spent reading English materials in relation to reading anxiety.

In a nutshell, although the results do not reflect a significant correlation, yet exploring the factors affecting the results is crucial in understanding learners' technique at acquiring the English language. Exploring variables such as reading anxiety, reading strategies and language competence adds to the pool of literature, especially when rural ESL learners are a concern.

\section{Conflicts of Interest}

The authors declare no conflicts of interest regarding the publication of this paper.

\section{References}

Acevedo, M. A. C., \& Forero, D. F. F. (2016). The Theory of the Six Readings: Promoting Reading Comprehension in English as a Foreign Language. MSc. Thesis, Bogota, DC: Universidad Libre.

Aisyah, J. (2017). Students' Reading Anxiety in English Foreign Language Classroom. Journal of English and Education, 5, 56-63.

Che Musa, N., Koo, Y. L., \& Azman, H. (2012). Exploring English Language Learning and Teaching in Malaysia. GEMA Online ${ }^{T M}$ Journal of Language Studies, 12, 35-51. http://journalarticle.ukm.my/3262/1/pp 35 51.pdf

Chen, K. T.-C., \& Chen, S. C.-L. (2015). The Use of EFL Reading Strategies among High School Students in Taiwan. The Reading Matrix: An International Online Journal, 15, 156-166. http://www.readingmatrix.com/files/13-m0137054.pdf

Cheng, X. T., \& Zhao, S. Q. (2016). The Connotations of Key Competences in English. Curriculum, Textbooks and Pedagogy, 6, 79-86.

Cresswell, J. W. (2012). Educational Research-Planning, Conducting and Evaluating Quantitative and Qualitative Research (4th ed.). Boston, MA: Pearson Education.

Darmi, R., \& Albion, P. R. (2013). English Language in Malaysian Education System: Its Existence and Implication. 3rd Malaysia Postgraduate Conference (MPC 2013), 4-5 July 2013, Sydney, Australia.

Deb, J. (2018). Affective Factors in Second Language Writing: Is It a Matter of Concern? The Morning Watch: Educational and Social Analysis, 46, 1-11.

Ellis, N. (2006). Selective Attention and Transfer Phenomena in L2 Acquisition: Contingency, Cue, Competition, Salience, Interference, Overshadowing, Blocking, and Perceptual Learning. Applied Linguistic, 27, 164-194.

https://doi.org/10.1093/applin/aml015

Horwitz, E. K., Horwitz, M. B., \& Cope, J. (1986). Foreign Language Classroom Anxiety. The Modern Language Journal, 70, 125-132. https://doi.org/10.1111/j.1540-4781.1986.tb05256.x

Hossain, M. I., Yagamaran, K. S., Afrin, T., Limon, N., Nasiruzzaman, M., \& Karim, A. M. (2018). Factors Influencing Unemployment among Fresh Graduates: A Case Study in Klang Valley, Malaysia. International Journal of Academic Research in Business and Social Sciences, 8, 1495-1507. https://doi.org/10.6007/IJARBSS/v8-i9/4859

Im, H.-J. (2015). The Use of Reading Strategy by Reading Anxiety and English Proficiency of Korean College Students. The Journal of the Korea Contents Association, 15, 
630-638. https://doi.org/10.5392/JKCA.2015.15.05.630

Karbalaei, A. (2015). The Study of the Relationship between Emotional Intelligence, Reading Motivation, and Anxiety with Reading Comprehension among Iranian EFL Learners. International Journal of English Language and Literature Studies, 4, 171-183. https://doi.org/10.18488/journal.23/2015.4.4/23.4.171.183

Karimi, M. N., Zangani, E., \& Fallah, N. (2019). Differential Allocation of Attention to Meaning and Form in Reading Comprehension for Monolingual and Bilingual Learners of English. TESOL International Journal, 14, 79-90.

Kilinc, H. H., \& Yenen, E. T. (2015). Investigation of Students' Reading Anxiety with Regards to Some Variables. International Journal of Higher Education, 5, 111-118. https://doi.org/10.5430/ijhe.v5n1p111

Kiya, R. M. (2015). The Effect of Second Language Learning Anxiety on Reading Comprehension of Iranian University Students. The International Journal of Humanities, 22, 53-85.

Krejcie, R. V., \& Morgan, D. W. (1970). Determining Sample Size for Research Activities. Educational and Psychological Measurement, 30, 607-610.

https://home.kku.ac.th

Liu, D. (2019). Students and Teacher Attitudes about Competence-Bases Instruction in Secondary English Classes in China. International Journal of Education and Social Science, 6, 28-34.

Maishara, N., Md. Rashid, S., Syed Zubir, S. I. S., \& Sadjirin, R. (2013). Differences in Reading Strategies: How ESL Learners Really Read. Procedia-Social and Behavioral Sciences, 90, 468-477. https://doi.org/10.1016/j.sbspro.2013.07.116

Manitoba Curriculum Framework of Outcomes (2007). Kindergarten to Grade 12 Aboriginal Language and Cultures. Winnipeg, Manitoba: Manitoba Education, Citizenship and Youth, School Programs Division.

Martinez, I. M. P. (1996). The Importance of Language Learning Strategies in Foreign Language Teaching. Cuadermos de Filologia Inglesa, 5, 103-120.

McGrath, L., Berggren, J., \& Mežek, Š. (2016). Reading EAP: Investigating High Proficiency L2 University Students' Strategy Use through Reading Blogs. Journal of English for Academic Purposes, 22, 152-164. https://doi.org/10.1016/j.jeap.2016.03.003

Mei, C., \& Michelle, H. (2014). The Relationships of Reading Anxiety and Reading Performance in Chinese People Learning English as a Second Language. Masters Report, Hong Kong: City University of Hong Kong.

Melanlioglu, D. (2014). Okuma kaygisi olceginin psikometrik ozelliklerinin belirlenmesi. Egitim ve Bilim Dergisi, 39, 95-105.

Mokhtari, K., \& Sheorey, R. (2002). Measuring ESL Students' Awareness of Reading Strategies. Journal of Development Education, 25, 2-10.

Mookiah, V., \& Yunus, M. M. (2016). The Preferred Second Language Learning Strategies of Good Language Learners in Rural Schools. In E-Proceedings of International Conference on Education 2016 (pp. 558-564). Kuching: Sarawak Association for the Development of Professionalism in Education.

Muhlis, A. (2017). Foreign Language Reading Anxiety. English Franca, 1, 19-44. http://www.jstor.org.libezproxy2.syr.edu/stable/330336?pq-origsite=summon\&seq $=1 \#$ p age scan tab contents

Nasrollahi, M. A., Krishnasamy, P. K. N., \& Noor, N. M. (2015). Process of Implementing Critical Reading Strategies in an Iranian EFL Classroom: An Action Research. International Education Studies, 8, 9-16. https://doi.org/10.5539/ies.v8n1p9 
Nik Mohd Fazreen Shah, A. S., Mohamad Hafizuddin, M., Mas Fairiziana, M. R., Nadzaty Akmar, A., Ainur Rizka, Y., Melor, M. Y., \& Maslawati, M. (2016). Investigating Interlingual Influence in Pupils' English Writings: A Case in Sarawak, Malaysia. In International Conference on Education Islamic Studies and Social Sciences Research.

Nordin, N. M., Rashid, S. M., Zubir, S. I. S. S., \& Sadjirin, R. (2013). Differences in Reading Strategies: How ESL Learners Really Read. Procedia-Social and Behavioral Sciences, 90, 468-477. https://doi.org/10.1016/j.sbspro.2013.07.116

Pascual, G. R. (2019). Reading Comprehension Performance of ESL Pre-Service Teachers as Influenced by Their Metacognitive Awareness Reading Strategies. International Journal of English and Education, 8, 34-51.

Qanwal, S., \& Karim, S. (2014). Identifying Correlation between Reading Strategies Instruction and L2 Text Comprehension. Journal of Language Teaching and Research, 5, 1019-1032. https://doi.org/10.4304/jltr.5.5.1019-1032

Rajab, A., Zarina, W., Zakaria, W., Abdul, H., \& Diyana, A. (2012). Reading Anxiety among Second Language Learners Reading Anxiety among Second Language Learners. Procedia-Social and Behavioral Sciences, 66, 362-369. https://doi.org/10.1016/j.sbspro.2012.11.279

Saito, Y., Horwitz, E. K., \& Garza, T. J. (1999). Foreign Language Reading Anxiety. The Modern Language Journal, 83, 202-218. https://doi.org/10.1111/0026-7902.00016

Sari, W. P., \& Sumatra, S. (2017). The Relationship between Reading Anxiety and Reading Strategy Used by EFL Student Teachers. Edukasi: Jurnal Pendidikan dan Pengajaran, 4, 1-9.

Schoenbach, R., Greenleaf, C., Cziko, C., \& Hurwitz, L. (1990). What Is Reading? An Excerpt from Reading for Understanding. San Francisco, CA: Jossey Bass. https://www.nwp.org/cs/public/download/nwp file/380/What is Reading - excerpt.p df? $\mathrm{x}-\mathrm{r}=\mathrm{pcfile} \mathrm{d}$

Semtin, S. A., \& Maniam, M. (2015). Reading Strategies among ESL Malaysian Secondary School Students. International Journal of Evaluation and Research in Education (IJERE), 4, 54-61.

Song, J. (2018). Relationships among Reading Anxiety, Reading Processing, and Reading Comprehension. Foreign Languages Education, 25, 83-113. https://doi.org/10.15334/fle.2018.25.2.83

Sultana, N. (2016). Assessing Reading Difficulties and Reading Strategies in the Context of Bangladesh: Tertiary Level. MSc Thesis, Dhaka, Bangladesh: BRAC University.

Zarei, A. A. (2014). The Effect of Reading Anxiety and Motivation on EFL Learners' Choice of Reading Strategies. Journal of Applied Linguistics and Language Research, 1, 12-28.

Zarei, A. A., \& Ghoushchi, S. (2018). The Effect of Corrective Feedback Types on Iranian Intermediate EFL Learners' L2 Reading Anxiety. English Language Studies Letters, 2, 40-47.

Zoghi, M. (2012). An Instrument for EFL Reading Anxiety: Inventory Construction and Preliminary Validation. The Journal of Asia TEFL, 9, 31-56.

Zoghi, M., \& Alivandivafa, M. (2014). EFL Reading Anxiety Inventory (EFLRAI). Journal of Psychoeducational Assessment, 32, 318-329.

https://doi.org/10.1177/0734282913513686 